\title{
Apomorphine induces mitochondrial-dysfunction-dependent apoptosis in choriocarcinoma
}

\author{
Jin-Young Lee ${ }^{1, *}$, Jiyeon $\mathrm{Ham}^{2, *}$, Whasun $\operatorname{Lim}^{3}$ and Gwonhwa Song(i) ${ }^{2}$ \\ ${ }^{1}$ Department of Pharmacology and Toxicology, Medical College of Wisconsin, Milwaukee, Wisconsin, USA, ${ }^{2}$ Institute \\ of Animal Molecular Biotechnology and Department of Biotechnology, College of Life Sciences and Biotechnology, \\ Korea University, Seoul, Republic of Korea and ${ }^{3}$ Department of Food and Nutrition, Kookmin University, Seoul, \\ Republic of Korea
}

Correspondence should be addressed to W Lim: ghsong@korea.ac.kr or to G Song: ghsong@korea.ac.kr

*(J-Y Lee and J Ham contributed equally to this work)

\begin{abstract}
Apomorphine is a derivative of morphine that is used for the treatment of Parkinson's disease because of its effects on the hypothalamus. Therapeutic effects of apomorphine have also been reported for various neurological diseases and cancers. However, the molecular mechanisms of the antitumor effects of apomorphine are not clear, especially with respect to choriocarcinoma. This is the first study to elucidate the anticancer effects of apomorphine on choriocarcinoma. We found that apomorphine suppressed the viability, proliferation, ATP production, and spheroid formation of JEG3 and JAR choriocarcinoma cells. Moreover, apomorphine activated the intrinsic apoptosis pathway by activating caspases and inhibited the production of anti-apoptotic proteins in choriocarcinoma cells. Further, apomorphine caused depolarization of mitochondria, calcium overload, energy deprivation, and endoplasmic reticulum stress in JEG3 and JAR cells. We confirmed synergistic effects of apomorphine with paclitaxel, a traditional chemotherapeutic agent, and propose that apomorphine could be a potential therapeutic agent in choriocarcinoma and an important candidate for drug repositioning that could help overcome resistance to conventional chemotherapy.

Reproduction (2020) 160 367-377
\end{abstract}

\section{Introduction}

Apomorphine, a quinoline alkaloid, is a degradation product of morphine. It is a dopamine receptor agonist and an alpha $(\alpha)$-adrenergic receptor antagonist (Millan et al. 2002). Apomorphine has been used to treat Parkinson's disease, and because of its inhibition of amyloid $\beta$ protein fiber formation, it has also been used to treat Alzheimer's disease (Himeno et al. 2011, Pessoa etal.2018, Pieroni 2019). Besides neurological disorders, apomorphine can also be used to target tumors (Auffret et al. 2019). It inhibits invasion of human breast cancer (MCF-7) cells, suppressing inflammation regardless of the presence of dopamine receptors (Ding \& Cui 2017). Additionally, it prevents metastasis of primary tumors, especially in the brain (Singh et al. 2018). Although its anticancer activity has been described for several tumors, there is no information about its therapeutic efficacy against choriocarcinoma cells.

Choriocarcinoma is a gestational trophoblastic cancer that usually originates in the placenta. It proliferates aggressively and metastasizes to other organs such as the lung, liver, or brain because of its hematogenous characteristics (Duong et al. 2018, Lee \& Cho 2019). Treatment of this gestational trophoblastic disease involves surgical resection, radiation, and chemotherapy; however, $25 \%$ of such cases have been reported to develop chemoresistance (Alazzam et al. 2016, Eysbouts et al. 2017). Although the combination of etoposide, methotrexate with folinic acid, and actinomycin $\mathrm{D} /$ cyclophosphamide and vincristine (EMA/CO) is used as first-line therapy, the development of chemoresistance results in treatment failure and even tumor recurrence (Alazzam et al. 2016). Thus, there is an urgent need to discover new therapeutic agents that have higher efficacy with lower side effects (Sato et al. 2020).

In this study, we aimed to study the anticancer effects of apomorphine on human JEG3 and JAR choriocarcinoma cells, especially with respect to synergy with traditional chemotherapeutic agents. Specifically, we sought to examine the effects of apomorphine on JEG3 and JAR cells with respect to (1) cell proliferation and viability, ATP production, and formation of spheroids; (2) caspasedependent apoptosis; (3) mitochondrial function and energy metabolism; (4) endoplasmic reticulum (ER) stress; and (5) synergy with paclitaxel. Therefore, we suggest that apomorphine could be used as a pharmacological agent for the treatment of human choriocarcinoma after 
the elucidation of its mechanism of anticancer activity. As apomorphine is already approved by the United States Food and Drug Administration to treat off-episode motor symptoms, our findings may contribute to its repositioning for choriocarcinoma treatment.

\section{Materials and methods}

\section{Chemicals and antibodies}

Apomorphine was purchased from Sigma-Aldrich. Hoechst 33342 (Cat. No: B2261) and propidium iodide (Cat. No: P4170) were purchased from Sigma-Aldrich, while carbobenzoxyvalyl-alanyl-aspartyl-(O-methyl)-fluoromethylketone (Z-VADFMK, Cat. No: 627610) was purchased from Calbiochem. Antibodies purchased from Cell Signaling Technology for Western blotting include myeloid cell leukemia 1 (Mcl1), B-cell lymphoma 2 (Bcl-2), B-cell lymphoma-extralarge (Bcl-xL), poly (adenosine diphosphate (ADP)-ribose) polymerase (PARP), cleaved PARP, $\beta$-actin, glucose-regulated protein-78/binding immunoglobulin protein (GRP78/Bip), activating transcription factor 4 (ATF4), and CCAAT/enhancer binding protein (C/EBP) homologous protein (CHOP).

\section{Cell maintenance and chemical treatment}

Human choriocarcinoma JEG3 and JAR cells were purchased from American Type Culture Collection (ATCC). Cells were maintained in RPMI 1640 medium supplemented with $10 \%$ fetal bovine serum (Hyclone) and 1\% penicillin-streptomycin at $37^{\circ} \mathrm{C}$ in a $5 \% \mathrm{CO}_{2}$ incubator. Cells were seeded at a concentration of $2 \times 10^{4} \mathrm{cells} / \mathrm{cm}^{2}$ and treated with various concentrations of apomorphine for $24 \mathrm{~h}$. Dimethyl sulfoxide was used as vehicle control.

\section{Measurement of cell viability and proliferation}

To measure the viability and proliferation of JEG 3 and JAR cells, the trypan blue exclusion assay was conducted to discriminate between viable and dead cells. ATP production was measured using a Cell Titer-Glo Luminescent assay (Promega) as an indicator of cell viability. This assay was performed according to the manufacturer's instructions.

\section{Spheroid formation}

For the spheroid formation assay, we seeded $100 \mu \mathrm{L}$ of JEG3 and JAR cells at a density of $1 \times 10^{5}$ cells $/ \mathrm{mL}$ in each well of a round bottom plate. Cells were treated with vehicle or $30 \mu \mathrm{M}$ of apomorphine and incubated at $37^{\circ} \mathrm{C}$ in a $5 \% \mathrm{CO}_{2}$ incubator for 5 days. Three-dimensional (3D) graphics images were obtained by using Image $J$ and Reconstruction and Visualization from a Single Projection (ReViSP) software.

\section{Detection of apoptotic cells}

Hoechst 33342 (Sigma-Aldrich) and propidium iodide (PI, Sigma-Aldrich) were used to detect apoptotic and necrotic cells. For measurement of caspase 3/7 enzyme activity, the
Caspase-Glo3/7 Assay (Promega) was performed according to the manufacturer's protocol. Cells were pretreated with $50 \mathrm{mM}$ of Z-VAD-FMK, the caspase inhibitor, for $1 \mathrm{~h}$. A fluorescein isothiocyanate (FITC) Annexin $\mathrm{V}$ apoptosis detection kit 1 (BD Biosciences) was used to analyze the cells using flow cytometry. Detailed protocols were described in previous studies (Lim et al. 2019).

\section{Western blot analysis}

Proteins were extracted from whole cells after treatment with apomorphine for $24 \mathrm{~h}$, and their concentrations were determined by using a Bradford protein assay (Bio-Rad). After denaturation, proteins were separated by sodium dodecyl sulfate-PAGE (SDS-PAGE) and then transferred to nitrocellulose membranes. Blots were quantified by chemiluminescence detection (SuperSignal West Pico, Pierce) using a ChemiDoc EQ system and Quantity One software (Bio-Rad). Detailed procedures were described in previous studies (Lim et al. 2019).

\section{Detection of mitochondrial membrane potential and relative mitochondrial calcium levels}

A mitochondrial staining kit (Sigma-Aldrich) was used to detect loss of mitochondrial membrane potential and the acetoxymethyl ester of Rhod-2 (Rhod-2 AM reagent, Thermo Fisher Scientific) was used as an indicator of mitochondrial calcium levels. Fluorescence signals were measured and analyzed by flow cytometry. To perform these assays, $2 \times 10^{4}$ cells $/ \mathrm{mL}$ of JEG3 and JAR cells were seeded in 6-well plates in $2 \mathrm{~mL}$ of complete media and incubated with apomorphine $(0,10,30$, and $50 \mu \mathrm{M})$ for $24 \mathrm{~h}$. Detailed procedures were described in previous studies (Lee et al. 2019b).

\section{Seahorse assay}

For mitochondrial stress analysis, we evaluated the oxygen consumption rate by studying oxidative phosphorylation. The sequential injection of oligomycin, carbonyl cyanide4-(trifluoromethoxy) phenylhydrazone (FCCP), rotenone, and antimycin A (mitochondrial complex I and III inhibitors) enabled the quantification of basal respiration, proton leak, maximal respiration, non-mitochondrial respiration, ATP production, and spare respiratory capacity using a Seahorse Analyzer and a mitochondrial stress analysis kit (Agilent Technologies). Detailed procedures were described in previous studies (Lee et al. 2018).

\section{Statistical analysis}

Data are expressed as mean \pm S.D., and significance was estimated by one-way or two-way ANOVA, as described in the figure legends. Post-hoc analyses were performed using GraphPad Prism 7 software. Statistical significance was indicated by $P<0.05$ and presented as follows in the legends: ${ }^{*} P<0.05, \quad{ }^{*} P<0.01, \quad{ }^{* * *} P<0.001 ;$ post-hoc analyses: Dunnett, Sidak). All histograms represent the mean \pm S.D. of at least three independent experiments. 


\section{Results}

\section{Apomorphine suppressed viability and proliferation of human choriocarcinoma JEG3 and JAR cells}

We evaluated the viability of JEG3 and JAR cells using trypan blue staining. Apomorphine gradually decreased the viability of JEG3 and JAR cells over $72 \mathrm{~h}$ in a dose-dependent manner (0 to $50 \mu \mathrm{M}$ ) (Fig. 1A). Treatment with apomorphine $(30 \mu \mathrm{M})$ for $24 \mathrm{~h}$ decreased the viability of JEG3 and JAR cells to
$57.5 \%$ and $69 \%$, respectively (Fig. 1A). Proliferation of JEG3 and JAR cells also decreased in response to apomorphine treatment $(0,10,30,50 \mu \mathrm{M})$ for $24 \mathrm{~h}$ (Fig. 1B). In addition, ATP production in both cell lines decreased significantly by $>50 \%$ with apomorphine treatment (Fig. 1C). Apomorphine completely inhibited the formation of tumor spheroids by up to $33 \%$ and $59 \%$ in JEG3 and JAR cell lines, respectively (Fig. 1D, $\mathrm{E}$ and F). This study demonstrates that apomorphine has strong anticancer effects and inhibits cell viability
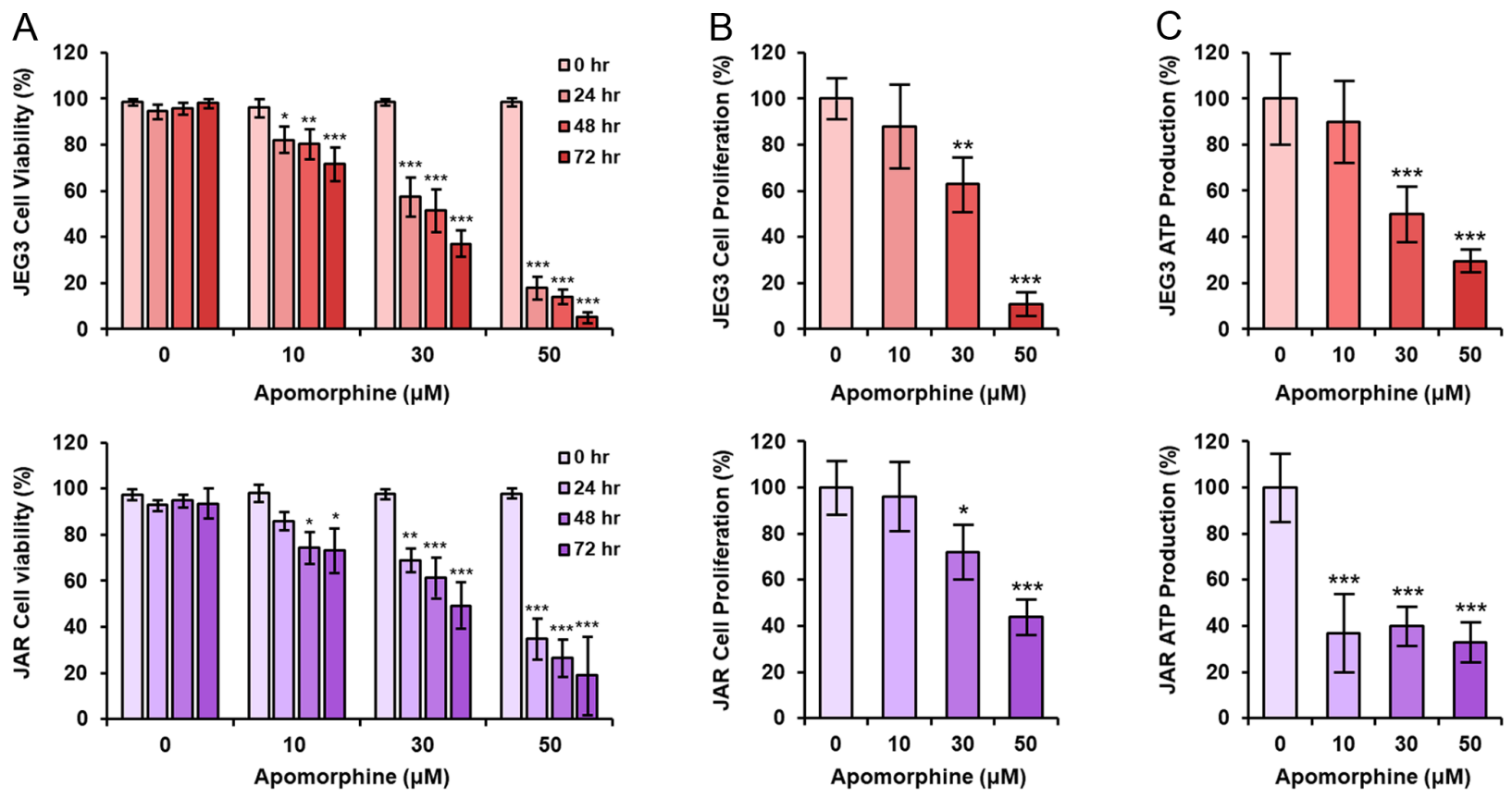

$\mathrm{D}$

E
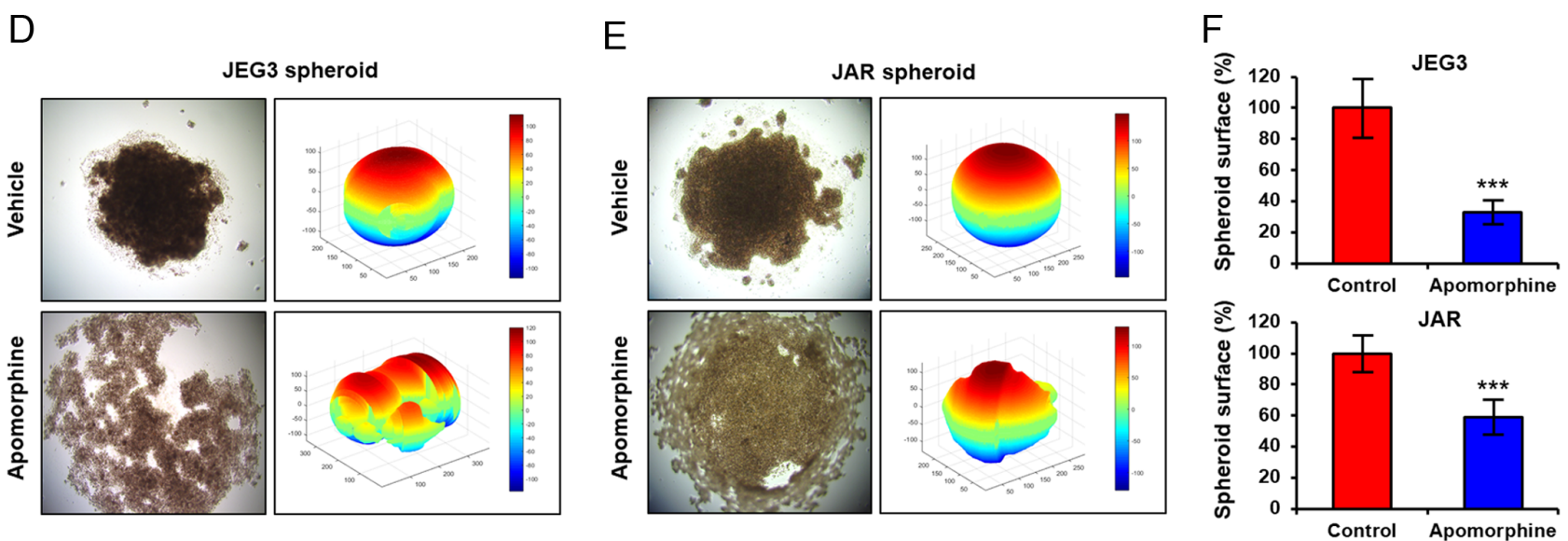

Figure 1 Antiproliferative effects of apomorphine on human choriocarcinoma JEG3 and JAR cells. (A) JEG3 and JAR cells were treated with apomorphine in a dose-dependent $(0,10,30$, and $50 \mu \mathrm{M})$ and time-dependent manner $(0,24,48$, and $72 \mathrm{~h})$. Viable cells were counted using trypan blue staining, and data from three independent experiments were subjected to statistical analysis. (B) Proliferation of JEG3 and JAR cells was measured by using the trypan blue exclusion assay after treatment with $30 \mu \mathrm{M}$ apomorphine for $24 \mathrm{~h}$. (C) Intracellular ATP levels in JEG3 and JAR cells were measured by colorimetric methods, as a response to various concentrations of apomorphine for $24 \mathrm{~h}$. (D, E and F) Vehicle or $30 \mu \mathrm{M}$ of apomorphine were incubated with JEG3 and JAR cells to study the effects on spheroid formation. 3D-structure images obtained using the ReViSP software are shown in the right panel. (F) Relative values of spheroid surface area are represented as bar graphs compared to control. Results are expressed as mean \pm S.D. of three independent experiments. Asterisk indicates a statistically significant difference between control and treatment, as analyzed by Dunnett's test, one-way analysis of variance (ANOVA) $(* P<0.05 ; * * P<0.01 ; * * * P<0.001)$. 
and proliferation of human choriocarcinoma JEG3 and JAR cells.

\section{Apomorphine induced caspase-dependent apoptosis in human choriocarcinoma JEG3 and JAR cells}

To verify the mechanism of cell death induced by apomorphine, we performed Hoechst 33342 and Annexin V/PI staining to detect apoptotic cells. Compared to vehicle-treated JEG3 or JAR cells, early and late apoptotic cells were detected based on their blue fragmented fluorescence and red fluorescence, respectively, after treatment with apomorphine (Fig. 2A and $B$ ). As indicated by the arrows, nuclear fragmentation was observed in both JEG3 and JAR cells in apomorphine treatments of $30 \mu \mathrm{M}$ and $50 \mu \mathrm{M}$, but not in the control group. These suggest, a hallmark of apoptotic cell death, that nuclear DNA is degraded into nucleosomal subunits. In JEG3 cells, flow cytometry using Annexin $\mathrm{V}$ and PI staining revealed significant increase in the number of early and late apoptotic cells (Fig. 2C and D). In JAR cells, the increase in late apoptotic and necrotic cells was induced by apomorphine treatment in a dose-dependent manner $(0,10,30$, and $50 \mu \mathrm{M})$ (Fig. 2C and D). To confirm whether intrinsic apoptosis was induced in JEG3 and JAR cells by apomorphine treatment, we measured caspase 3 and 7 activity (Fig. 2E). In both apomorphine-treated choriocarcinoma cell lines, caspase $3 / 7$ activity was dramatically increased $(>2 \times)$. This apomorphine-induced caspase $3 / 7$ activity was significantly inhibited by pretreatment with the pan-caspase inhibitor, Z-VAD-FMK, which implies that apomorphine induced caspase-dependent apoptosis in both cell lines (Fig. 2E). Thus, we confirmed that apomorphine induced intrinsic apoptotic cell death in human choriocarcinoma cells.
A

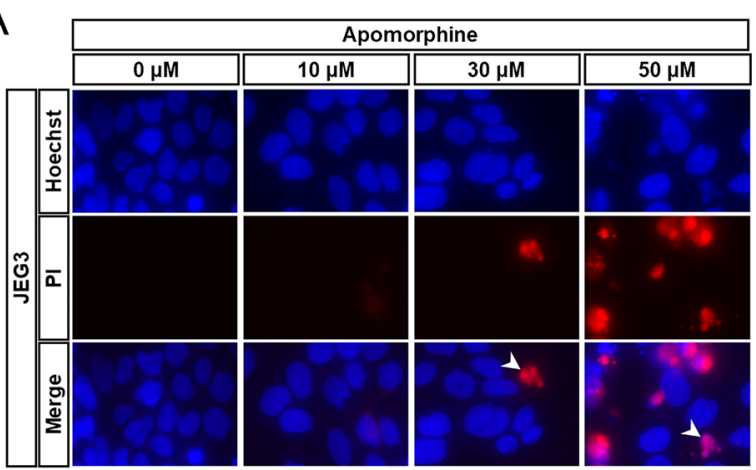

C

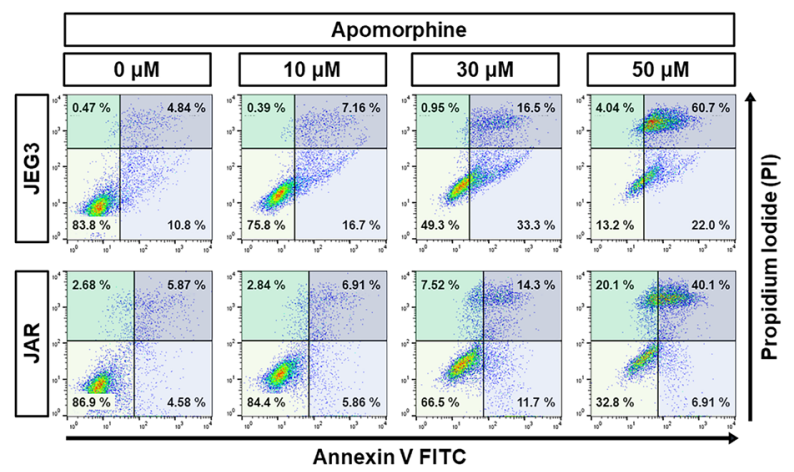

B

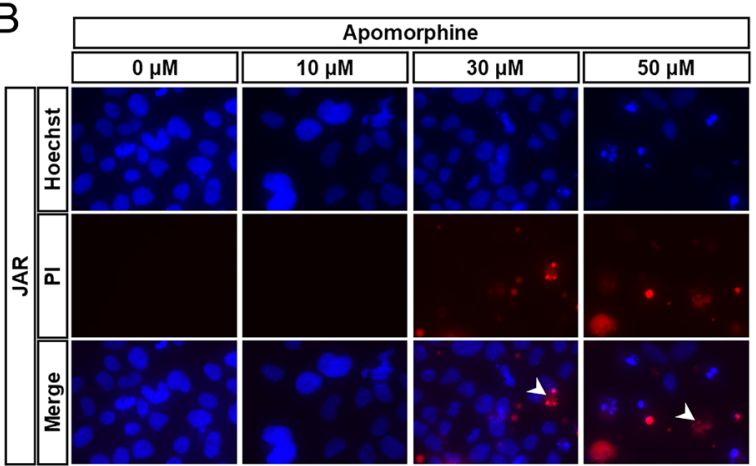

$\mathrm{D}$

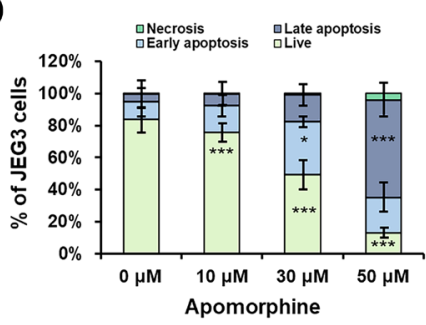

E
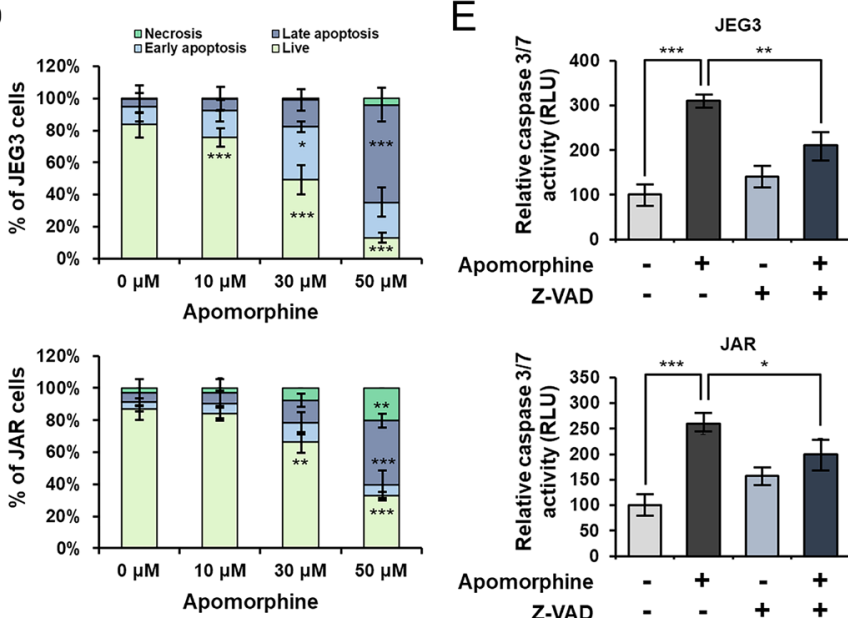

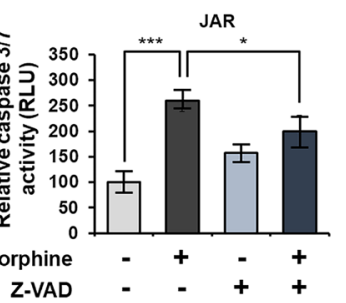

Figure 2 Effects of apomorphine on cell death in JEG3 and JAR choriocarcinoma cells. (A and B) To determine changes in morphological characteristics caused by apomorphine, JEG3 and JAR cells were stained with Hoechst 33342 (upper panel, blue) and propidium iodide (PI, middle panel, red). (C) Cell death patterns in apomorphine-treated JEG3 and JAR cells were analyzed using Annexin V and PI staining and flow cytometry. (D) Relative cell populations of live (lower left panel), early apoptotic (lower right panel), late apoptotic (upper right panel), and necrotic (upper left panel) cells were analyzed using fluorescence-activated cell sorting (FACS) data. (E) Caspase 3/7 activity was measured in 30- $\mu \mathrm{M}$-apomorphine-treated JEG3 (upper panel) and JAR cells (lower panel) compared to vehicle-treated cells. Further, cells were pretreated with Z-VAD-FMK, a caspase inhibitor, for $1 \mathrm{~h}$ before incubation with apomorphine. Results are expressed as mean \pm S.D. of three independent experiments. Asterisk indicates a statistically significant difference between control and treatment, as analyzed by Dunnett's test, one-way (D), or two-way (E) analysis of variance (ANOVA) $\left({ }^{*} P<0.05 ; * * P<0.01 ; * * * P<0.001\right)$. 
Apomorphine regulated levels of anti-apoptotic proteins, leading to intrinsic apoptosis in JEG3 and JAR cells

We performed Western blotting to detect the levels of proteins of the intrinsic apoptosis pathway in JEG3 and JAR cells. Levels of the anti-apoptotic Bcl-2 family proteins, $\mathrm{Mcl}-1$ and $\mathrm{BCl}-2$, were significantly decreased by $10 \mu \mathrm{M}$ of apomorphine in JEG3 cells (Fig. $3 \mathrm{~A}$ and $\mathrm{B}$. Apomorphine decreased $\mathrm{BCl}-\mathrm{xL}$ levels in a dosedependent manner $(0,10,30$, and $50 \mu \mathrm{M})$ (Fig. 3A and B); even lower concentrations of apomorphine inhibited $\mathrm{Bcl}-2$ protein levels in JEG3 cells to $<30 \%$ of those in untreated cells (Fig. 3B). Apomorphine also decreased protein levels of $\mathrm{Mcl}-1, \mathrm{BCl}-2$, and $\mathrm{BCl}-\mathrm{xL}$ in JAR cells (Fig. 3C and D). In contrast, levels of cleaved PARP, the pro-apoptotic marker, were increased in apomorphinetreated JEG3 and JAR cells (Fig. 3A, B, C and D). Thus, we demonstrate that apomorphine activated the intrinsic apoptosis pathway in JEG3 and JAR cells and regulated apoptotic protein levels.

\section{Apomorphine caused mitochondrial dysfunction and metabolic changes in JEG3 and JAR cells}

Mitochondrial function is crucial for cell survival and plays a major role in apoptotic cell death. Hence, we investigated mitochondrial membrane potential, calcium uptake, and metabolic homeostasis in JEG3 and JAR cells. Relative mitochondrial membrane potential (MMP, $\Delta \Psi)$ and calcium uptake of mitochondria were dramatically modulated by $50 \mu \mathrm{M}$ of apomorphine in JEG3 cells, leading to depolarization and increased calcium uptake, respectively (Fig. 4A and C). The extent of depolarization (decrease in MMP) and mitochondrial calcium levels were gradually increased by apomorphine in JAR cells (Fig. 4B and D). The effects of apomorphine on mitochondrial respiration and glycolysis in choriocarcinoma cells were examined by analyzing the bioenergetics profile using oligomycin, an ATP synthase inhibitor; FFCP, a depolarizer of plasma membrane potential; and rotenone and antimycin A, complex I and III inhibitors, respectively (Fig. 4E). In both JEG3 and JAR cells treated with $30 \mu \mathrm{M}$ of apomorphine for $24 \mathrm{~h}$, basal/maximal respiration levels and ATP production decreased considerably compared to those of the vehicle-treated cells (Fig. 4F). The bioenergetics phenotype of JEG3 and JAR choriocarcinoma cells changed from energetic to quiescent with reduced glycolytic function after treatment of $30 \mu \mathrm{M}$ of apomorphine (Fig. 4G). This energy profile supports our data for the inhibition of proliferation and ATP reduction by apomorphine treatment. Therefore, as mitochondrial dysfunction is considered an important
A

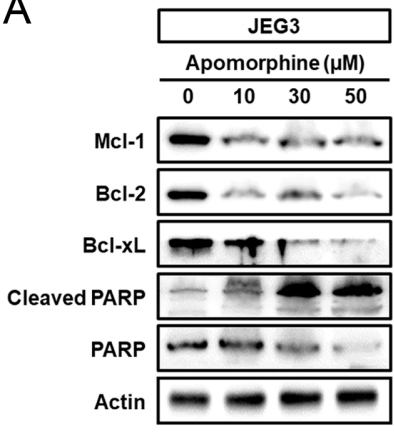

C

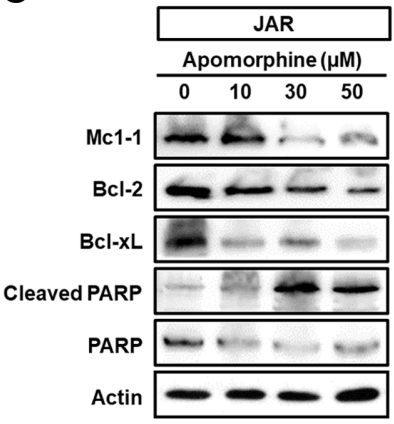

B

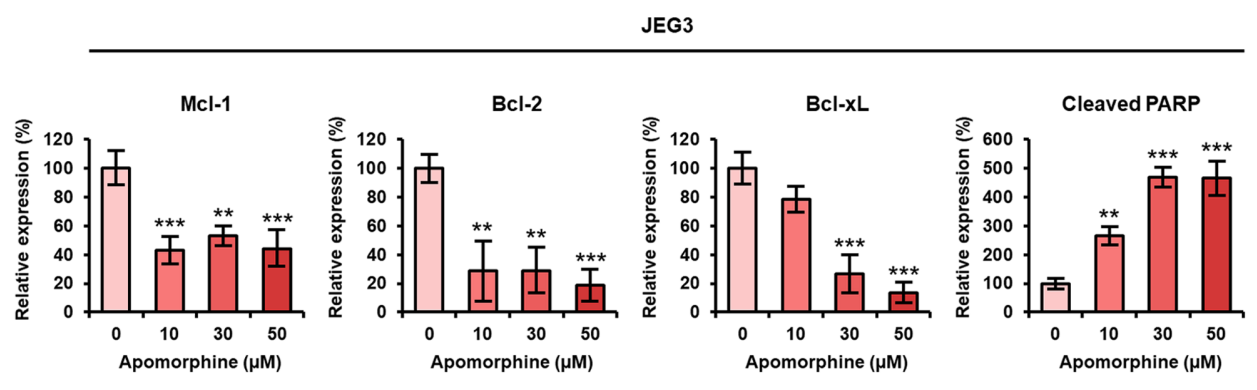

D

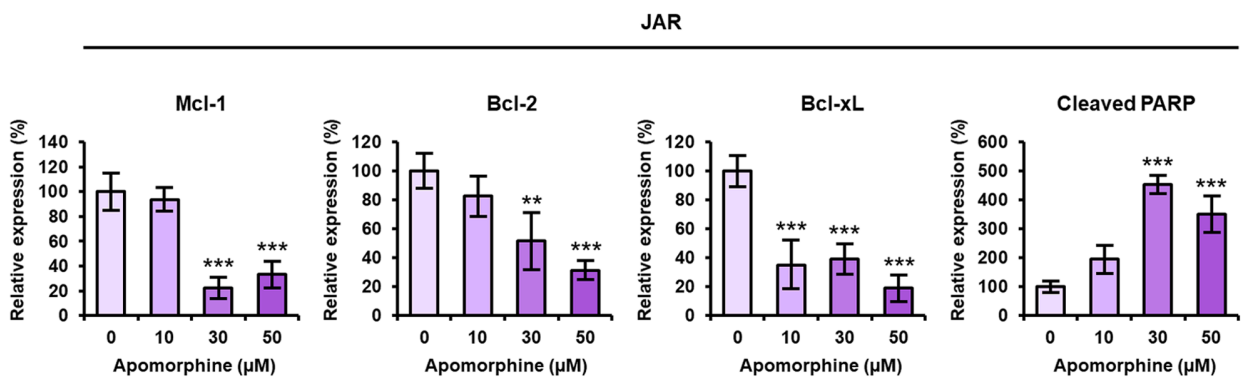

Figure 3 Apoptosis-related changes in protein levels induced by apomorphine in human choriocarcinoma JEG3 and JAR cells. (A and C) Immunoblots of JEG3 and JAR cells treated with various concentrations of apomorphine (0, 10, 30, and $50 \mu \mathrm{M})$ for $24 \mathrm{~h}$. (B and D) Relative protein levels of Mcl-1, Bcl-2, Bcl-xL, PARP, and cleaved PARP in human choriocarcinoma cells (JEG3, JAR) were analyzed using Image Lab software and represented as bar graphs compared to control cells. Results are expressed as mean \pm S.D. of three independent experiments. Asterisk indicates a statistically significant difference between control and treatment, as analyzed by Dunnett's test, one-way analysis of variance (ANOVA) $\left({ }^{*} P<0.05 ; * * P<0.01 ; * * * P<0.001\right)$. 


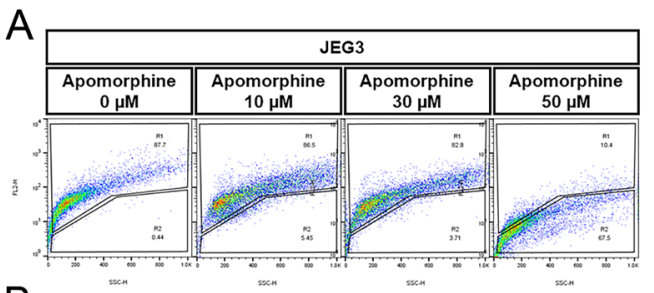

B

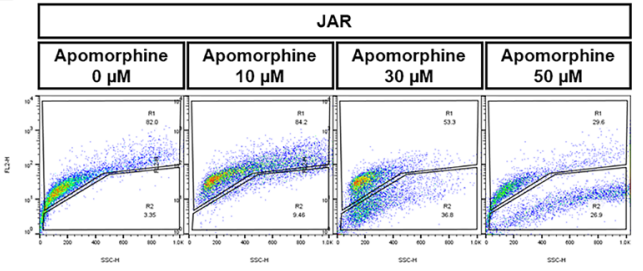

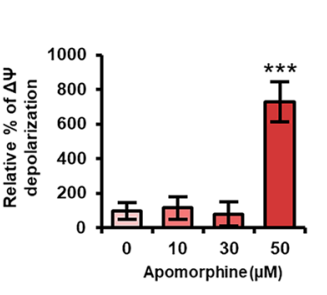
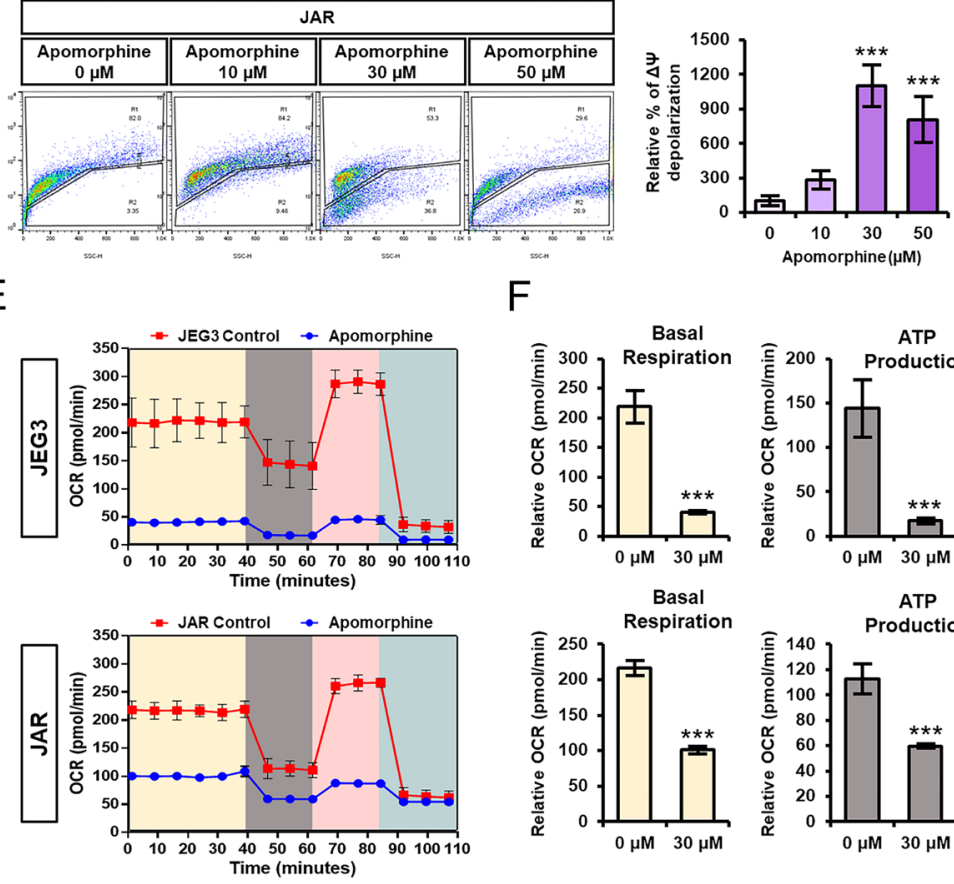

$\mathrm{F}$
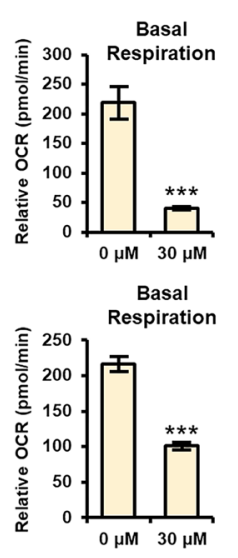

C

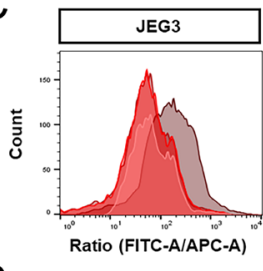

D

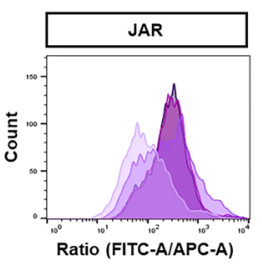

G
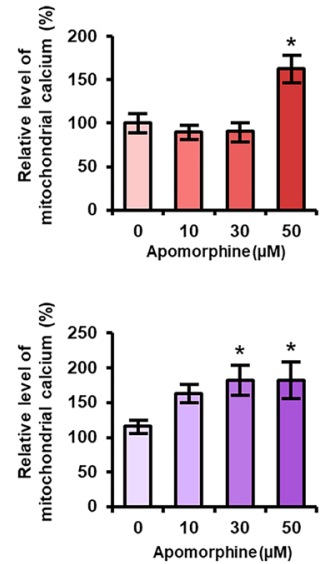
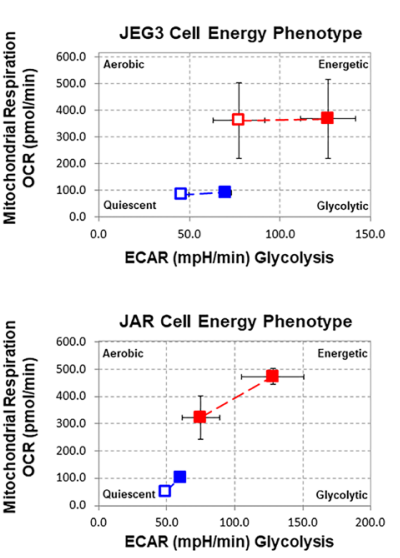

Figure 4 Effects of apomorphine on mitochondrial function and energy metabolism in human choriocarcinoma cells. (A and B) Depolarization of $\Delta \Psi$ was detected by JC- 1 dye staining in JEG 3 and JAR cells ( $\Delta \Psi$; mitochondrial membrane potential). Cells detected in $R^{2}$ area of cytometry data were analyzed and represented as bar graphs (right panel) relative to vehicle-treated cells. (C and D) Increase in mitochondrial calcium levels in apomorphine-treated JEG3 and JAR cells were detected by Rhod-2 staining and analyzed using flow cytometry. (E) Metabolic profiles of apomorphine-treated JEG3 and JAR cells were analyzed by a Seahorse analyzer. (F) Basal respiration, ATP production, and maximal respiration values of JEG3 and JAR cells were measured based on the Seahorse assay. (G) Changes in energy phenotype of JEG3 and JAR cells treated with apomorphine $(30 \mu \mathrm{M})$ were analyzed based on the results of the Seahorse assay. Results are expressed as mean \pm S.D. of three independent experiments. Asterisk indicates a statistically significant difference between control and treatment, as analyzed by Dunnett's test, one-way analysis of variance (ANOVA) $\left({ }^{*} P<0.05 ;{ }^{* *} P<0.01 ; * * * P<0.001\right)$.

representative feature of intrinsic apoptosis, these data may indicate apomorphine-induced activation of specific apoptosis pathways in choriocarcinoma cells. Taken together, apomorphine exhibited anticancer effects on human choriocarcinoma cells by inducing mitochondrial dysfunction, as evidenced by loss of MMP and disruption of calcium homeostasis and energy balance. Mitochondrial apoptosis is defined by mitochondrial outer membrane depolarization leading transcriptional regulation of $\mathrm{BH} 3$-only proteins, proteasomal degradation, apoptosome formation, and caspase activation, and our results suggested most of the characteristics (Lopez \& Tait 2015). Considering mitochondria is a key organelle to regulate the energy process, we speculated that mitochondrial apoptosis may eventually cause metabolic shifting, in particular oxidative phosphorylation (OXPHOS)
(Porporato et al. 2018). In agreement with our hypothesis, apomorphine-induced systematic mitochondrial dysfunction triggers mitochondrial apoptosis, which contributes to metabolic alteration by loss of OXPHOS in placental choriocarcinoma cells.

\section{Apomorphine induced endoplasmic reticulum stress in human choriocarcinoma JEG3 and JAR cells}

As endoplasmic reticulum (ER) stress is known to be a major factor in the induction of apoptosis by interactions with mitochondria, we performed Western blotting to examine the protein levels of ER stress signaling molecules. Protein levels of an initiation marker of ER stress, GRP78/Bip, were increased 8-fold in JEG3 and 2-fold in JAR cells after treatment with $50 \mu \mathrm{M}$ apomorphine (Fig. 5A and C). Levels of ATF4 and CHOP, 


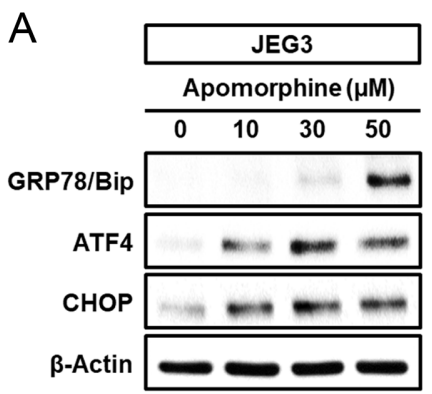

C

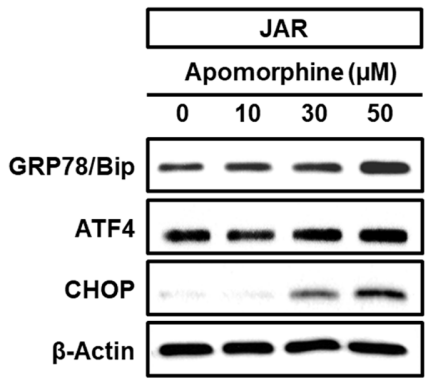

B

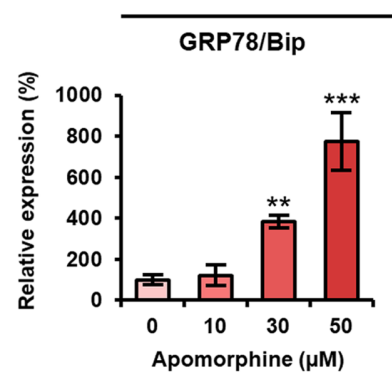

$\mathrm{D}$

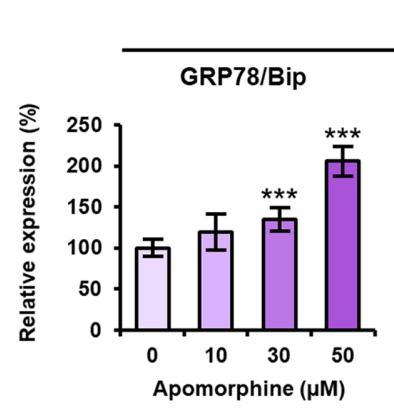

JEG3
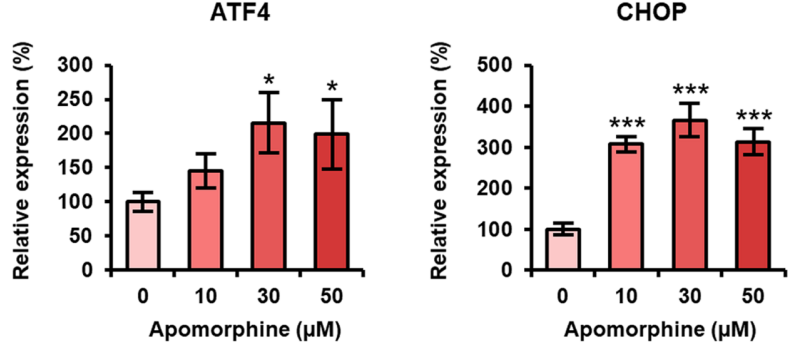

JAR

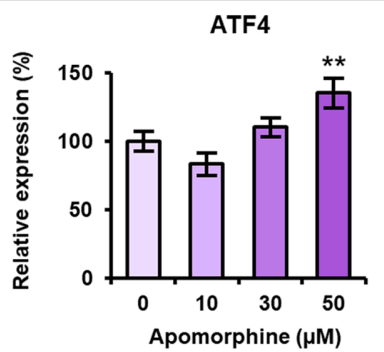

CHOP

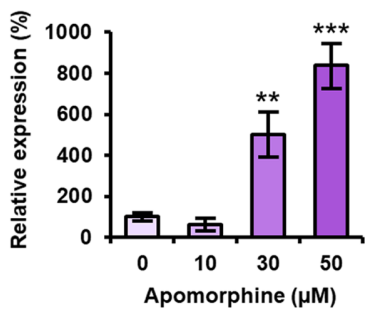

Figure 5 Effects of apomorphine on ER stress signaling proteins in choriocarcinoma cells. (A and C) Immunoblots of JEG3 and JAR cells treated with various concentrations of apomorphine $(0,10,30$, and $50 \mu \mathrm{M})$ for $24 \mathrm{~h}$. (B and D) Relative protein levels in immunoblots of GRP78/Bip, ATF4, and CHOP in choriocarcinoma cells (JEG3, JAR cells) were analyzed using the same methods used for the experiments depicted in Fig. 3. Results are expressed as mean \pm S.D. of three independent experiments. Asterisk indicates a statistically significant difference between control and treatment, as analyzed by Dunnett's test, one-way analysis of variance (ANOVA) $\left({ }^{*} P<0.05 ; * * P<0.01 ;{ }^{* * *} P<0.001\right)$.

transcription factors and downstream signal molecules of ER stress increased to 2.1-fold and 3.7-fold in JEG3 cells, respectively (Fig. 5B). In JAR cells, apomorphine treatment increased ATF4 and CHOP levels (Fig. 5D). These results suggest that ER stress induced by apomorphine led to mitochondria-mediated intrinsic apoptosis of choriocarcinoma JEG3 and JAR cells.

\section{Apomorphine exhibited synergistic anticancer effects with paclitaxel in human choriocarcinoma cells}

To determine whether apomorphine could enhance chemosensitivity in choriocarcinoma cells, we added paclitaxel, a standard chemotherapeutic agent, to our experiments. In both JEG3 and JAR cells, the number of apoptotic and necrotic cells significantly increased in the combined treatment compared to single treatment of apomorphine or paclitaxel (Fig. 6A and B). Co-treatment with apomorphine $(10,30 \mu \mathrm{M})$ and paclitaxel $(0.1,0.5$ $\mu \mathrm{M})$ revealed synergistic effects on the viability of JEG3 and JAR cells (Fig. 6C and D). The combination index (Cl) and fraction affected (FA) values of these combination treatments were calculated. In all co-treatment conditions, $\mathrm{Cl}$ values were $<1$ in both JEG3 and JAR cells, which indicated that the relationship between paclitaxel and apomorphine was synergistic (Fig. 6E and F). These results suggest the efficacy of apomorphine as a therapeutic agent for human choriocarcinoma cells, both for its anticancer effects and as an agent for those cancers that have become resistant to traditional chemotherapeutic agents.

\section{Discussion}

Apomorphine was initially developed for the treatment of Parkinson's disease for its effects on the hypothalamus and its activity as a dopaminergic receptor agonist. Besides these effects on the brain and neuronal disease, there is no comprehensive assessment of apomorphine that targets gynecological disease; however, there is interesting research that supports our hypothesis. Dopamine abrogates the secretion of human chorionic gonadotropin (hCG) in human placental culture (Macaron et al. 1979). Human chorionic gonadotropin plays a crucial role in angiogenesis via transforming growth factor-beta activation in the placenta at the maternal and fetal interface during early pregnancy and stimulates choriocarcinoma in the same biological frame (Berndt et al. 2013). Ectopic expression of beta-hCG ( $\beta$-hCG) demonstrates a paradoxical function in its stimulation of cancer growth (Giovangrandi et al. 2001, Nagirnaja et al. 2010). As the inhibition of hCG secretion in the human placenta and trophoblast by dopamine is well characterized, we hypothesized that a dopaminergic receptor agonist might effectively inhibit the growth of 


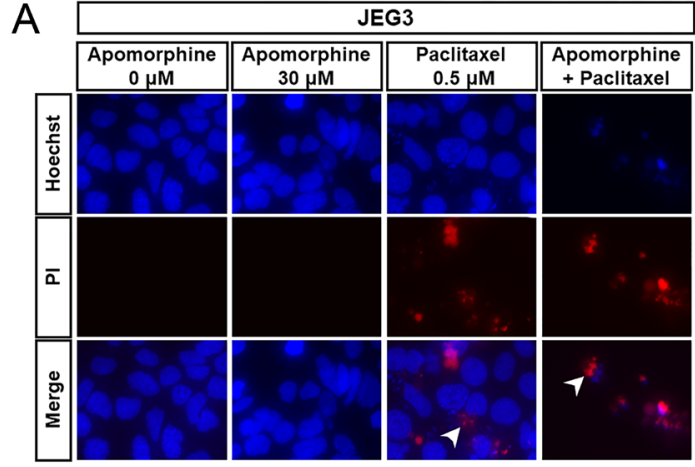

$\mathrm{B}$

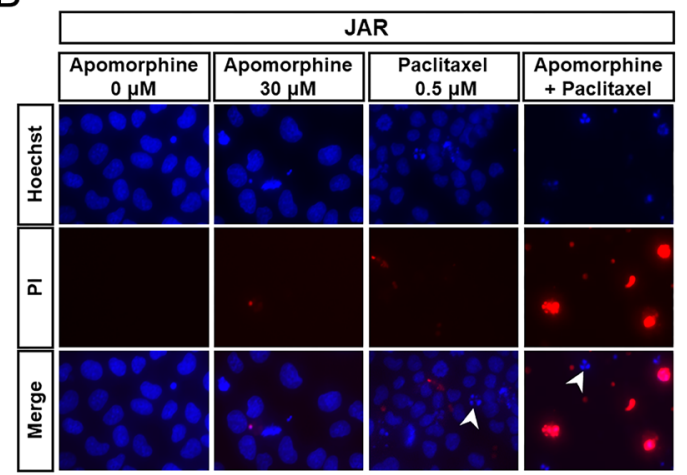

C

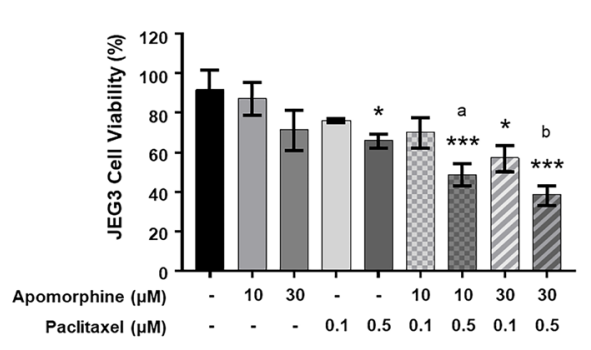

D

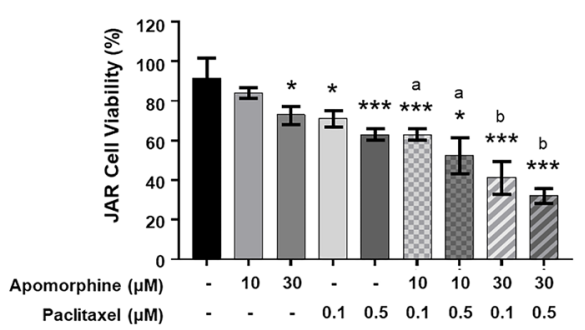

$\mathrm{E}$

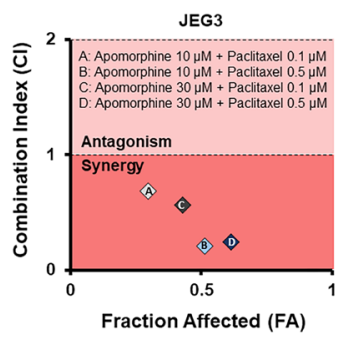

$\mathrm{F}$

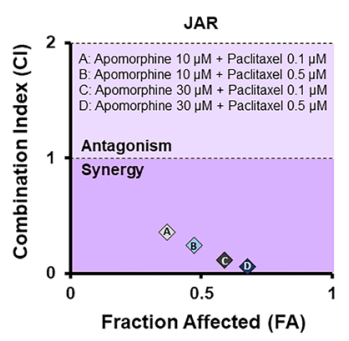

Figure 6 Synergistic effects of combined treatment with apomorphine and paclitaxel on choriocarcinoma cells. (A and B) Hoechst 33342 and propidium iodide (PI) staining was carried out after combined treatment of JEG3 and JAR cells with apomorphine $(30 \mu \mathrm{M})$ and paclitaxel $(0.5 \mu \mathrm{M})$. (C and D) Different concentrations of apomorphine $(10,30 \mu \mathrm{M})$ and paclitaxel $(0.1,0.5 \mu \mathrm{M})$ were combined to confirm synergistic effects on the inhibition of cell viability of JEG3 and JAR cells. (E and F) Through CompuSyn software analysis, combination index (CI) and fraction affected (FA) values were calculated to indicate synergistic relationship between apomorphine and paclitaxel toward JEG3 and JAR cells. Results are expressed as mean \pm S.D. of three independent experiments. Asterisk indicates a statistically significant difference between control and treatment, as analyzed by Dunnett's test, two-way analysis of variance (ANOVA) $\left({ }^{*} P<0.05 ;{ }^{* *} P<0.01 ; * * * P<0.001\right)$. Lowercase letters indicate statistically significant differences of treatments: a, compared with $10 \mu \mathrm{M}$ apomorphine alone; b, compared with $30 \mu \mathrm{M}$ apomorphine alone.

choriocarcinoma cells and contribute to increasing the susceptibility of these cells to chemotherapy.

Efforts to discover new antitumor drugs are ongoing and focus on combining standard chemotherapeutic agents, combining them with bioactive natural products or finding new indications of drugs already being used for other diseases (Lee et al. 2016, Chikara et al. 2018, Riedel et al. 2018). Apomorphine, a dopaminergic agonist and derivative of morphine, has been used as a remedial agent for Parkinson's disease and also for neurological disease, sexual disorders, and cancers (Auffret et al. 2019). A few decades ago, there were reports about the cytotoxicity of apomorphine toward brain glioma of rat (El-Bacha et al. 1999). Apomorphine also shows antitumor effects on human breast cancer and anti-metastatic effects on brain metastases (Jung \& Lee 2017, Singh et al. 2018). Aporphine, which shares the quinolone alkaloid structure of apomorphine, induces caspase-dependent apoptosis in head/neck squamous cell carcinoma (Rodrigues-Junior et al. 2020). Apomorphine also suppresses the binding of mouse double minute 2 homolog (MDM2) to p53 (Ishiba et al. 2017), which restores WT p53 function (Wiman 2006,
Vassilev 2007). The increase in p53 activity, as a tumor suppressor, leads to apoptosis with cell cycle arrest and inhibits cell migration by regulating microRNA in choriocarcinoma JEG3 cells, which supports our hypothesis of the anticancer activity of apomorphine toward choriocarcinoma cells (Drukteinis et al. 2005, Lu et al. 2020).

In this study, we demonstrate that apomorphine induced caspase-dependent apoptosis in human choriocarcinoma cells and caused global mitochondrial dysfunction. Serial caspase activation was initiated by the release of cytochrome $c$, leading to the formation of apoptosomes. This was accompanied by a decrease in MMP and in the production of anti-apoptotic proteins (Fu et al. 2017). Mcl-1 and $\mathrm{Bcl}-\mathrm{xL}$ are pro-survival proteins belonging to the $\mathrm{Bcl}-2$ family of proteins and are involved in drug resistance (Lee et al. 2019a). Mcl-1 is a key indicator of drug resistance in myeloma, prostate cancer, and fibroblast-like synoviocytes (Punnoose et al. 2016, Jiao et al. 2018, Pilling \& Hwang 2019). Our results show decreased protein levels of $\mathrm{Bcl}-2$ family members, $\mathrm{Mcl}-1, \mathrm{BCl}-2$, and $\mathrm{BCl}-\mathrm{xL}$, indicating the initiation of mitochondrial apoptosis in choriocarcinoma 


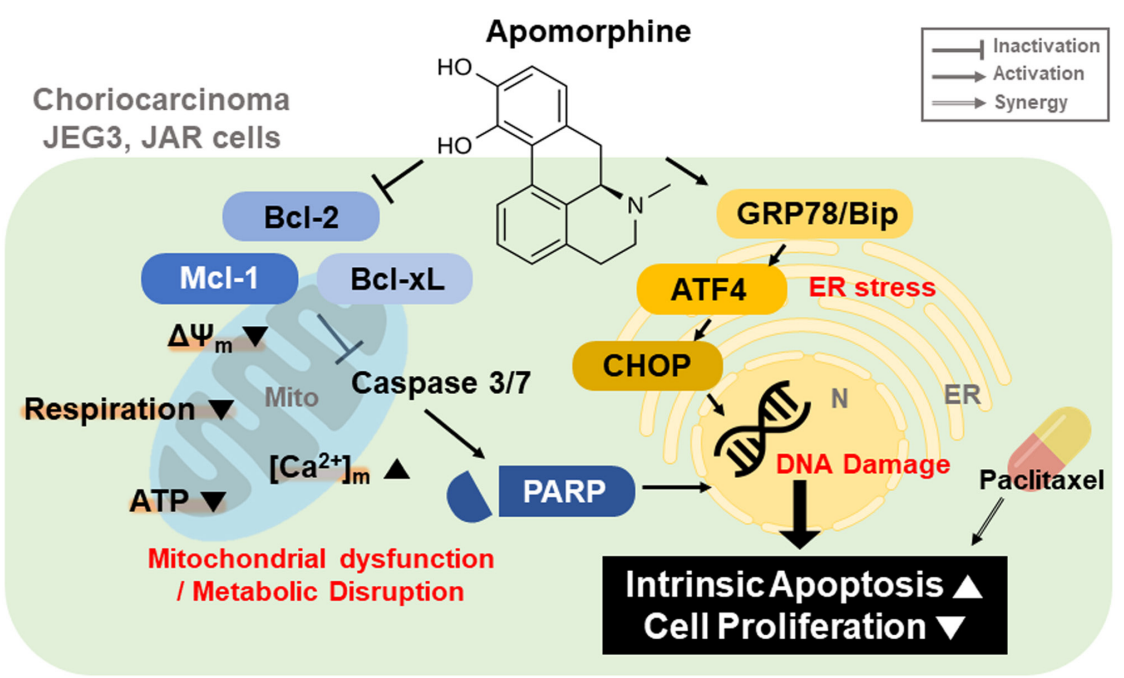

Figure 7 Illustration about possible mechanisms of anticancer activity of apomorphine in human choriocarcinoma JEG3 and JAR cells. Mito, mitochondria; ER, endoplasmic reticulum; $N$, Nucleus; $\Delta \Psi$, mitochondrial membrane potential; $\left(\mathrm{Ca}^{2+}\right)_{\mathrm{m} \prime}$ mitochondrial calcium level. cells. Cleaved PARP levels, the last step of the caspase activation pathway, were also elevated, which indicated a reduction in DNA repair capacity (Li \& Darzynkiewicz 2000). Loss of MMP and mitochondrial calcium overload are typical characteristics of intrinsic apoptosis, which were also observed in our study (Szabadkai \& Rizzuto 2004, Fischer et al. 2008).

Further, we examined the metabolic effects of apomorphine in choriocarcinoma cells, which could be targeted to enhance drug sensitivity. For instance, reactive oxygen species-induced apoptosis in leukemia cells was increased by co-treatment with agents inhibiting mitochondrial respiration (Pelicano et al. 2003). Although there was no specific bioenergetics profile for choriocarcinoma, we observed the suppression of a shift to a glycolytic energy phenotype by apomorphine. Cancer cells prefer aerobic glycolysis to generate their energy rapidly; this phenomenon is known as the Warburg effect (Liberti \& Locasale 2016). Targeting the Warburg effect has also been used as an anticancer therapeutic strategy (El Sayed et al. 2013, Chen et al. 2016), for example, the disruption of mitochondrial bioenergetics with the pharmacological inhibitor, mitochondrial division inhibitor-1 (MDIVI-1), efficiently induces breast cancer cell death (Lucantoni et al. 2018).

Mitochondria and ER are closely interacted with each other and share functions such as the regulation of calcium homeostasis or cellular stress (Szabadkai \& Rizzuto 2004, Senft \& Ronai 2015, Marchi et al. 2018). As Bcl-2 family proteins affect the release of calcium from ER (Kuwana \& Newmeyer 2003), we examined whether apomorphine treatment could cause ER stress in choriocarcinoma cells. The GRP78/Bip protein regulates unfolded protein response in response to cellular stress. The protein kinase RNA-like endoplasmic reticulum kinase (PERK)/ATF4/CHOP pathway is activated as an ER stress signal, and ATF4/CHOP subsequently suppresses the production of $\mathrm{BCl}-2$ proteins, which is also consistent with our observations (Rozpedek et al. 2016). Moreover, through mitochondrial-associated ER membranes (MAM), calcium is transferred from the mitochondria to the ER, leading to calcium overload, which then induces apoptosis (Pinton et al. 2008, BravoSagua et al. 2013). Similarly, prolonged ER stress disrupts cellular metabolism and mitochondrial functions, which also eventually leads to apoptosis (Gupta et al. 2010, Bravo et al. 2012). Thus, in the present study, we show that apomorphine induced intrinsic apoptosis through mitochondrial dysfunction and ER stress in choriocarcinoma cells.

Paclitaxel is a member of the taxane family and had been used for the treatment of high-risk choriocarcinoma in combination with other chemotherapeutic agents (Marth et al. 1995, Joshua et al. 2004). However, paclitaxel possesses side effects, especially in pregnant patients, in whom it could cause birth defects (Berveiller \& Mir 2012). Thus, combining paclitaxel with other chemotherapeutic agents can not only minimize its side effects because of its dose reduction, but also maximize the anticancer effects due to the combination of drugs. Therefore, our observations on the antiproliferative effects of apomorphine in combination with paclitaxel suggest a new therapeutic strategy to treat chemoresistant choriocarcinoma.

In the current study, we investigated apomorphine as an anticancer agent for choriocarcinoma cells, as illustrated in Fig. 7. Apomorphine showed antiproliferative effects on JEG3 and JAR cells and inhibited spheroid formation, a simulation of in vivo antiproliferative activity. Apomorphine caused mitochondriamediated intrinsic apoptosis in choriocarcinoma via mitochondrial dysfunction and energy deprivation. We also demonstrated a reduction in the levels of antiapoptotic proteins and induction of ER stress. Moreover, we confirmed synergistic effects of apomorphine in combination with paclitaxel, which could be used to treat chemoresistant choriocarcinoma. Taken together, 
our findings suggest that apomorphine is a novel anticancer agent against human choriocarcinoma cells and set the stage for drug repositioning of apomorphine for choriocarcinoma treatment.

\section{Declaration of interest}

The authors declare that there is no conflict of interest that could be perceived as prejudicing the impartiality of the research reported.

\section{Funding}

This research was supported by a grant of the National Research Foundation of Korea (NRF) grant, funded by the Ministry of Science and ICT (MSIT) (grant number: 2018R1C1B6009048).

\section{Author contribution statement}

G S, W L and J Y L conceived and designed the culture experiments, the cell culture methodology, and all other experiments; J Y L and J H collected experimental samples and conducted all experiments; JY L, W L, and G S analysed, interpreted the data and contributed to the development of the manuscript. All authors contributed to its critical review and agreed on the final version.

\section{References}

Alazzam M, Tidy J, Osborne R, Coleman R, Hancock BW \& Lawrie TA 2016 Chemotherapy for resistant or recurrent gestational trophoblastic neoplasia. Cochrane Database of Systematic Reviews 2016 CD008891. (https://doi.org/10.1002/14651858.CD008891.pub3)

Auffret M, Drapier S \& Verin M 2019 New tricks for an old dog: a repurposing approach of apomorphine. European Journal of Pharmacology 843 66-79. (https://doi.org/10.1016/j.ejphar.2018.10.052)

Berndt S, Blacher S, Munaut C, Detilleux J, Perrier DS, Huhtaniemi I, Evain-brion D, Noel A, Fournier T \& Foidart JM 2013 Hyperglycosylated human chorionic gonadotropin stimulates angiogenesis through TGFbeta receptor activation. FASEB Journal 27 1309-1321. (https://doi. org/10.1096/fj.12-213686)

Berveiller P \& Mir O 2012 Taxanes during pregnancy: probably safe, but still to be optimized. Oncology 83 239-240. (https://doi. org/10.1159/000341820)

Bravo-sagua R, Rodriguez AE, Kuzmicic J, Gutierrez T, Lopez-crisosto C, Quiroga C, Diaz-elizondo J, Chiong M, Gillette TG, Rothermel BA et al. 2013 Cell death and survival through the endoplasmic reticulummitochondrial axis. Current Molecular Medicine 13 317-329. (https:// doi.org/10.2174/156652413804810781)

Bravo R, Gutierrez T, Paredes F, Gatica D, Rodriguez AE, Pedrozo Z, Chiong M, Parra V, Quest AF, Rothermel BA et al. 2012 Endoplasmic reticulum: ER stress regulates mitochondrial bioenergetics. International Journal of Biochemistry and Cell Biology 44 16-20. (https://doi. org/10.1016/j.biocel.2011.10.012)

Chen XS, Li LY, Guan YD, Yang JM \& Cheng Y 2016 Anticancer strategies based on the metabolic profile of tumor cells: therapeutic targeting of the Warburg effect. Acta Pharmaceutica Sinica 37 1013-1019. (https://doi. org/10.1038/aps.2016.47)

Chikara S, Nagaprashantha LD, Singhal J, Horne D, Awasthi S \& Singhal SS 2018 Oxidative stress and dietary phytochemicals: role in cancer chemoprevention and treatment. Cancer Letters 413 122-134. (https:// doi.org/10.1016/j.canlet.2017.11.002)

Ding YX \& Cui H 2017 Integrated analysis of genome-wide DNA methylation and gene expression data provide a regulatory network in intrauterine growth restriction. Life Sciences 179 60-65. (https://doi. org/10.1016/j.Ifs.2017.04.020)

Drukteinis JS, Medrano T, Ablordeppey EA, Kitzman JM \& Shiverick KT 2005 Benzo[a]pyrene, but not 2,3,7,8-TCDD, induces G2/M cell cycle arrest, p21CIP1 and p53 phosphorylation in human choriocarcinoma JEG-3 cells: a distinct signaling pathway. Placenta 26 (Supplement A) S87-S95. (https://doi.org/10.1016/j.placenta.2005.01.013)

Duong J, Ghanchi H, Miulli D \& Kahlon A 2018 Metastatic nongestational choriocarcinoma to the brain: case report and proposed treatment recommendations. World Neurosurgery 115 170-175. (https://doi. org/10.1016/j.wneu.2018.04.050)

El-bacha RS, Netter P \& Minn A 1999 Mechanisms of apomorphine cytoxicity towards rat glioma C6 cells: protection by bovine serum albumin and formation of apomorphine-protein conjugates. Neuroscience Letters $\mathbf{2 6 3}$ 25-28. (https://doi.org/10.1016/S0304-3940(99)00088-9)

El SSM, Mahmoud AA, El SSA, Abdelaal EA, Fouad AM, Yousif RS, Hashim MS, Hemdan SB, Kadry ZM, Abdelmoaty MA et al. 2013 Warburg effect increases steady-state ROS condition in cancer cells through decreasing their antioxidant capacities (anticancer effects of 3-bromopyruvate through antagonizing Warburg effect). Medical Hypotheses 81 866-870. (https://doi.org/10.1016/j.mehy.2013.08.024)

Eysbouts YK, Massuger L, Inthout J, Lok CAR, Sweep F \& Ottevanger PB 2017 The added value of hysterectomy in the management of gestational trophoblastic neoplasia. Gynecologic Oncology 145 536-542. (https:// doi.org/10.1016/j.ygyno.2017.03.018)

Fischer TW, Zmijewski MA, Wortsman J \& Slominski A 2008 Melatonin maintains mitochondrial membrane potential and attenuates activation of initiator (casp-9) and effector caspases (casp-3/casp-7) and PARP in UVR-exposed HaCaT keratinocytes. Journal of Pineal Research 44 397-407. (https://doi.org/10.1111/j.1600-079X.2007.00542.x)

Fu Y, Ye X, Lee M, Rankin G \& Chen YC 2017 Prodelphinidins isolated from chinese bayberry leaves induces apoptosis via the p53-dependent signaling pathways in OVCAR-3 human ovarian cancer cells. Oncology Letters 13 3210-3218. (https://doi.org/10.3892/ol.2017.5813)

Giovangrandi Y, Parfait B, Asheuer M, Olivi M, Lidereau R, Vidaud M \& Bieche I 2001 Analysis of the human CGB/LHB gene cluster in breast tumors by real-time quantitative RT-PCR assays. Cancer Letters 168 93-100. (https://doi.org/10.1016/S0304-3835(01)00496-7)

Gupta S, Cuffe L, Szegezdi E, Logue SE, Neary C, Healy S \& Samali A 2010 Mechanisms of ER stress-mediated mitochondrial membrane permeabilization. International Journal of Biochemistry and Cell Biology 2010170215.

Himeno E, Ohyagi Y, Ma L, Nakamura N, Miyoshi K, Sakae N, Motomura K, Soejima N, Yamasaki R, Hashimoto T et al. 2011 Apomorphine treatment in Alzheimer mice promoting amyloid-beta degradation. Annals of Neurology 69 248-256. (https://doi.org/10.1002/ana.22319)

Ishiba H, Noguchi T, Shu K, Ohno H, Honda K, Kondoh Y, Osada H, Fujii N \& Oishi S 2017 Investigation of the inhibitory mechanism of apomorphine against MDM2-p53 interaction. Bioorganic and Medicinal Chemistry Letters 27 2571-2574. (https://doi.org/10.1016/j. bmcl.2017.03.082)

Jiao Y, Ding H, Huang S, Liu Y, Sun X, Wei W, Ma J \& Zheng F 2018 $\mathrm{BCl}-\mathrm{XL}$ and $\mathrm{Mcl}-1$ upregulation by calreticulin promotes apoptosis resistance of fibroblast-like synoviocytes via activation of PI3K/Akt and STAT3 pathways in rheumatoid arthritis. Clinical and Experimental Rheumatology 36 841-849.

Joshua AM, Carter JR \& Beale P 2004 The use of taxanes in choriocarcinoma: a case report and review of the literature. Gynecologic Oncology $\mathbf{9 4}$ 581-583. (https://doi.org/10.1016/j.ygyno.2004.05.036)

Jung YS \& Lee SO 2017 Apomorphine suppresses TNF-alpha-induced MMP-9 expression and cell invasion through inhibition of ERK/ AP-1 signaling pathway in MCF-7 cells. Biochemical and Biophysical Research Communications 487 903-909. (https://doi.org/10.1016/j. bbrc.2017.04.151)

Kuwana T \& Newmeyer DD 2003 Bcl-2-family proteins and the role of mitochondria in apoptosis. Current Opinion in Cell Biology 15 691-699. (https://doi.org/10.1016/j.ceb.2003.10.004)

Lee E \& Cho H 2019 A case of intraplacental choriocarcinoma with pulmonary metastasis. Case Reports in Oncology 12 802-806. (https:// doi.org/10.1159/000503816)

Lee EF, Harris TJ, Tran S, Evangelista M, Arulananda S, John T, Ramnac C, Hobbs C, Zhu H, Gunasingh G et al. 2019a BCL-XL and MCL-1 are the 
key BCL-2 family proteins in melanoma cell survival. Cell Death and Disease 10 342. (https://doi.org/10.1038/s41419-019-1568-3)

Lee H, Kang S \& Kim W 2016 Drug repositioning for cancer therapy based on large-scale drug-induced transcriptional signatures. PLOS ONE 11 e0150460. (https://doi.org/10.1371/journal.pone.0150460)

Lee JY, Lim W, Park S, Kim J, You S \& Song G 2019b Deoxynivalenol induces apoptosis and disrupts cellular homeostasis through MAPK signaling pathways in bovine mammary epithelial cells. Environmental Pollution 252 879-887. (https://doi.org/10.1016/j.envpol.2019.06.001)

Lee JY, Talhi O, Jang D, Cerella C, Gaigneaux A, Kim KW, Lee JW, Dicato M, Bachari K, Han BW et al. 2018 Cytostatic hydroxycoumarin OT52 induces ER/Golgi stress and STAT3 inhibition triggering non-canonical cell death and synergy with $\mathrm{BH} 3$ mimetics in lung cancer. Cancer Letters 416 94-108. (https://doi.org/10.1016/j.canlet.2017.12.007)

Li X \& Darzynkiewicz Z 2000 Cleavage of poly(ADP-ribose) polymerase measured in situ in individual cells: relationship to DNA fragmentation and cell cycle position during apoptosis. Experimental Cell Research 255 125-132. (https://doi.org/10.1006/excr.1999.4796)

Liberti MV \& Locasale JW 2016 The Warburg effect: how does it benefit cancer cells? Trends in Biochemical Sciences 41 211-218. (https://doi. org/10.1016/j.tibs.2015.12.001)

Lim W, Ham J, Bazer FW \& Song G 2019 Carvacrol induces mitochondriamediated apoptosis via disruption of calcium homeostasis in human choriocarcinoma cells. Journal of Cellular Physiology 234 1803-1815. (https://doi.org/10.1002/jcp.27054)

Lopez J \& Tait SW 2015 Mitochondrial apoptosis: killing cancer using the enemy within. British Journal of Cancer 112 957-962. (https://doi. org/10.1038/bjc.2015.85)

Lu W, Ma YY, Shao QQ, Liang J, Qi TT, Huang Y \& Wang QJ 2020 ROS/p53/ miR3355p/Sp1 axis modulates the migration and epithelial to mesenchymal transition of JEG3 cells. Molecular Medicine Reports 3 1208-1216.

Lucantoni F, Dussmann H \& Prehn JHM 2018 Metabolic targeting of breast cancer cells with the 2-deoxy-D-glucose and the mitochondrial bioenergetics inhibitor MDIVI-1. Frontiers in Cell and Developmental Biology 6 113. (https://doi.org/10.3389/fcell.2018.00113)

Macaron C, Kyncl M, Famuyiwa O, Halpern B \& Brewer J 1979 In vitro effect of dopamine and pimozide on human chorionic gonadotropin secretion. American Journal of Obstetrics and Gynecology 135 499-502. (https://doi.org/10.1016/0002-9378(79)90439-3)

Marchi S, Patergnani S, Missiroli S, Morciano G, Rimessi A, Wieckowski MR, Giorgi C \& Pinton P 2018 Mitochondrial and endoplasmic reticulum calcium homeostasis and cell death. Cell Calcium 69 62-72. (https://doi. org/10.1016/j.ceca.2017.05.003)

Marth C, Lang T, Widschwendter M, Muller-holzner E \& Daxenbichler G 1995 Effects of taxol on choriocarcinoma cells. American Journal of Obstetrics and Gynecology 173 1835-1842. (https://doi. org/10.1016/0002-9378(95)90437-9)

Millan MJ, Maiofiss L, Cussac D, Audinot V, Boutin JA \& Newmantancredi A 2002 Differential actions of antiparkinson agents at multiple classes of monoaminergic receptor. I. A multivariate analysis of the binding profiles of 14 drugs at 21 native and cloned human receptor subtypes. Journal of Pharmacology and Experimental Therapeutics 303 791-804. (https://doi.org/10.1124/jpet.102.039867)

Nagirnaja L, Rull K, Uuskula L, Hallast P, Grigorova M \& Laan M 2010 Genomics and genetics of gonadotropin beta-subunit genes: unique FSHB and duplicated LHB/CGB loci. Molecular and Cellular Endocrinology 329 4-16. (https://doi.org/10.1016/j.mce.2010.04.024)

Pelicano H, Feng L, Zhou Y, Carew JS, Hileman EO, Plunkett W, Keating MJ \& Huang P 2003 Inhibition of mitochondrial respiration: a novel strategy to enhance drug-induced apoptosis in human leukemia cells by a reactive oxygen species-mediated mechanism. Journal of Biological Chemistry 278 37832-37839. (https://doi.org/10.1074/jbc. M301546200)

Pessoa RR, Moro A, Munhoz RP, Teive HAG \& Lees AJ 2018 Apomorphine in the treatment of Parkinson's disease: a review. Arquivos de NeuroPsiquiatria 76 840-848. (https://doi.org/10.1590/0004-282×20180140)
Pieroni MA 2019 Investigation of apomorphine during sleep in Parkinson's: improvement in UPDRS scores. Neurology International 118207. (https://doi.org/10.4081/ni.2019.8207)

Pilling AB \& Hwang C 2019 Targeting prosurvival BCL2 signaling through akt blockade sensitizes castration-resistant prostate cancer cells to enzalutamide. Prostate $\mathbf{7 9}$ 1347-1359. (https://doi.org/10.1002/ pros.23843)

Pinton P, Giorgi C, Siviero R, Zecchini E \& Rizzuto R 2008 Calcium and apoptosis: ER-mitochondria Ca2+ transfer in the control of apoptosis. Oncogene 27 6407-6418. (https://doi.org/10.1038/onc.2008.308)

Porporato PE, Filigheddu N, Pedro JMB, Kroemer G \& Galluzzi L 2018 Mitochondrial metabolism and cancer. Cell Research 28 265-280. (https://doi.org/10.1038/cr.2017.155)

Punnoose EA, Leverson JD, Peale F, Boghaert ER, Belmont LD, Tan N, Young A, Mitten M, Ingalla E, Darbonne WC et al. 2016 Expression profile of $B C L-2, B C L-X L$, and $M C L-1$ predicts pharmacological response to the BCL-2 selective antagonist venetoclax in multiple myeloma models. Molecular Cancer Therapeutics 15 1132-1144. (https://doi. org/10.1158/1535-7163.MCT-15-0730)

Riedel T, Demaria O, Zava O, Joncic A, Gilliet M \& Dyson PJ 2018 Drug repurposing approach identifies a synergistic drug combination of an antifungal agent and an experimental organometallic drug for melanoma treatment. Molecular Pharmaceutics 15 116-126. (https:// doi.org/10.1021/acs.molpharmaceut.7b00764)

Rodrigues-Junior DM, De APNM, De AGE, Carlin V, Perecim GP, Raminelli C \& Vettore AL 2020 Assessment of the cytotoxic effects of aporphine prototypes on head and neck cancer cells. Investigational New Drugs 38 70-78. (https://doi.org/10.1007/s10637-019-00784-6)

Rozpedek W, Pytel D, Mucha B, Leszczynska H, Diehl JA \& Majsterek I 2016 The role of the PERK/elF2alpha/ATF4/CHOP signaling pathway in tumor progression during endoplasmic reticulum stress. Current Molecular Medicine 16 533-544. (https://doi.org/10.2174/1566524016 666160523143937)

Sato S, Yamamoto E, Niimi K, Ino K, Nishino K, Suzuki S, Kotani T, Kajiyama H \& Kikkawa F 2020 The efficacy and toxicity of 4-day chemotherapy with methotrexate, etoposide and actinomycin D in patients with choriocarcinoma and high-risk gestational trophoblastic neoplasia. International Journal of Clinical Oncology 25 203-209. (https://doi.org/10.1007/s10147-019-01540-9)

Senft D \& Ronai ZA 2015 UPR, autophagy, and mitochondria crosstalk underlies the ER stress response. Trends in Biochemical Sciences $\mathbf{4 0}$ 141-148. (https://doi.org/10.1016/j.tibs.2015.01.002)

Singh M, Venugopal C, Tokar T, Mcfarlane N, Subapanditha MK, Qazi M, Bakhshinyan D, Vora P, Murty NK, Jurisica I et al. 2018 Therapeutic targeting of the premetastatic stage in human lung-to-brain metastasis. Cancer Research 78 5124-5134. (https://doi.org/10.1158/0008-5472. CAN-18-1022)

Szabadkai G \& Rizzuto R 2004 Participation of endoplasmic reticulum and mitochondrial calcium handling in apoptosis: more than just neighborhood? FEBS Letters 567 111-115. (https://doi.org/10.1016/j. febslet.2004.04.059)

Vassilev LT 2007 MDM2 inhibitors for cancer therapy. Trends in Molecular Medicine 13 23-31. (https://doi.org/10.1016/j.molmed.2006.11.002)

Wiman KG 2006 Strategies for therapeutic targeting of the p53 pathway in cancer. Cell Death and Differentiation 13 921-926. (https://doi. org/10.1038/sj.cdd.4401921)

Received 26 April 2020

First decision 27 May 2020

Revised manuscript received 28 May 2020

Accepted 9 June 2020 